\title{
Utility of Medical and Drug History in Fracture Risk Prediction Among Men and Women
}

\author{
T. P. van STAA, ${ }^{1,2,3}$ H. G. M. LEUFKENS, ${ }^{2}$ and C. COOPER ${ }^{1}$ \\ ${ }^{1}$ Medical Research Council Environmental Epidemiology Unit, University of Southampton, Southampton General Hospital, Southampton, UK \\ ${ }^{2}$ Department of Pharmacoepidemiology and Pharmacotherapy, University of Utrecht, Utrecht, The Netherlands \\ ${ }^{3}$ Procter \& Gamble Pharmaceuticals, Staines, UK
}

Preventive strategies against osteoporotic fracture depend, in part, on the availability of simple risk prediction tools whereby pharmacological therapy may be targeted to those at greatest risk. The objective of this study was to evaluate the performance of a series of risk factors routinely listed in primary care records for the prediction of future fracture. Information was obtained from the UK General Practice Research Database, which contains the general practitioner medical records of around $6 \%$ of the UK population. We performed a case-control study of all 231,778 adult patients with a recorded fracture between 1988 and 1999 and an equal number of controls, individually matched by age, gender, and medical practice to the cases. In addition to a previous history of fracture, 11 items were identified that independently predicted fracture risk (history of anemia, dementia, cerebrovascular disease, and chronic obstructive pulmonary disease; recent use of oral corticosteroids, anticonvulsants, nonsteroidal anti-inflammatory drugs [NSAIDs], antiarrythmics, hypnotics/anxiolytics, antidepressants, and anti-Parkinson drugs). Three or more of these medical risk factors increased the risk of a vertebral fracture 8.1 times (95\% confidence interval [CI] 7.0-9.4) and of hip fracture by 4.6 times (95\% CI 4.3-5.0), when compared with subjects without these attributes. The optimum screening characteristics of the risk factors for prediction of vertebral fracture revealed a sensitivity $66 \%$, and specificity $89 \%$. These values were $61 \%$ and $68 \%$, respectively, for hip fracture. The positive predictive value (PPV) for fracture over a 5 year period improved with the addition of age and previous fracture history to the number of medical risk factors. PPV rose from $8.4 \%$ for women aged 65 years without risk factors or fracture history, compared with $26.8 \%$ if women had sustained a previous fracture and had three or more risk factors recorded. The data suggest that routinely recorded medical risk factors permit identification of groups of patients with a substantial increase in future risk of fracture. Further investigations, such as bone densitometry, might be conveniently targeted at this group of patients. (Bone 31: 508-514; 2002) (C) 2002 by Elsevier Science Inc. All rights reserved.

Address for correspondence and reprints: Prof. Cyrus Cooper, MRC Environmental Epidemiology Unit, University of Southampton, Southampton General Hospital, Southampton SO16 6YD, UK. E-mail: cc@mrc.soton.ac.uk
Key Words: Epidemiology; Osteoporosis; Risk factors; Screening.

\section{Introduction}

Osteoporosis is clinically recognized by the occurrence of fractures, most frequently those of the hip, vertebral body, and distal forearm, which are associated with considerable morbidity. ${ }^{5,14}$ Preventive strategies against these fractures typically include population-wide measures to improve lifestyle, as well as a high-risk approach in which subjects at the greatest risk of osteoporosis are identified so that pharmacological interventions might be cost-effectively targeted. Although bone densitometry remains our most efficient tool for detection of subjects at risk, mass screening using bone density measurement is not justifiable given the low frequency of fractures in the general population, and the uncertain cost utility of targeting interventions using this investigation alone. ${ }^{13,16} \mathrm{~A}$ number of other risk factors for osteoporotic fracture have been identified, but there is no validated proforma for incorporating these in high-risk strategies. Among these, age, a previous history of fracture, and a variety of medical risk factors (drugs and diseases), are routinely recorded in the primary care setting, and have been shown to predict the risk of future fracture. ${ }^{9}$ The performance of a risk-stratifying tool based on these medical risk factors has not been rigorously evaluated. We therefore utilized the General Practice Research Database to identify important independent risk factors for future fracture; to evaluate their performance as a predictive tool; and to explore the extent to which this predictive capacity might be enhanced by inclusion of age and previous fracture history. If validated, such an algorithm could easily be adapted for selective case detection in routinely obtained primary care data.

\section{Methods}

The data utilized in this case-control study were obtained from the General Practice Research Database (GPRD), managed by the Medicines Control Agency in the UK. ${ }^{24}$ This database comprises the entire computerized medical records of a sample of general practitioners in the country. General practitioners (GPs) play a key role in the UK health-care system, as they are responsible for primary health care and specialist referrals. All members of the population are registered with a single practice, which centralizes the medical information not only from the GPs themselves but also from specialist referrals and hospital attendances. The current study included 683 practices currently incorporated in the GPRD, and thereby comprised a $6 \%$ sample of 
the UK population. The data recorded in the GPRD included demographic information, prescription details, clinical events, preventive care provided, specialist referrals, and hospital admissions and their major outcomes. Clinical data are stored and retrieved by means of Oxford Medical Information Systems (OXMIS) and Read codes for diseases that are cross referenced to the International Classification of Diseases (ICD-9). The data quality of each entry into the GPRD is measured against specific targets, developed by comparisons with external statistics, to ensure research standards are met. Only data from practices that pass this quality control are compiled to form the GPRD database. ${ }^{24}$ Several independent validation studies have confirmed a high level of completeness and validity of the GPRD, specifically with regard to recording of fractures. ${ }^{22,24}$ The overall incidence patterns in the study population of these fractures have been described elsewhere. ${ }^{23}$

\section{Study Population}

A nested case-control study was conducted comparing patients with a fracture to control patients. The cases were permanently registered patients aged $\geq 18$ year who had a fracture recorded in their medical record during the period of time from the enrollment date of their practice in GPRD up to end of study (July 1999). The control patients were patients without a history of fractures in the medical records, who were matched by age (within 1 year), gender, and medical practice. If no control patient was found, the age criterion was expanded consecutively with 1 year intervals, up to a maximum of 10 years. In the event of no eligible control patient within 10 years of age, an age- and gender-matched control patient was selected from another practice. The index date of each control patient was that of the matched case (i.e., first fracture after their enrollment in the GPRD). For the small number of control patients who had transferred to another practice or died prior to this date, an index date was randomly selected between registration and transfer dates. The classification of fractures was based on categories of the ninth revision of the International Classification of Diseases (ICD-9). ${ }^{23}$

\section{Risk Factors}

The risk factors considered included a broad group of diseases and drugs that might be associated with an increased risk of fracture. ${ }^{21}$ These included a history of diabetes mellitus, rheumatoid arthritis, congestive heart failure, anemia, dementia, cerebrovascular disease, falls, back pain, and chronic obstructive pulmonary disease. Prescriptions for oral corticosteroids, anticonvulsants, nonsteroidal anti-inflammatory drugs (NSAIDs), thiazide diuretics, antiarrythmics, anxiolytics, antipsychotics, antidepressants, anti-Parkinson drugs, and inhaled corticosteroids or bronchodilators, in the 6 months prior to the index date (and specifically, without including information on the index date) were also ascertained. Adjusted odds ratios (ORs) of fracture were estimated using a conditional logistic regression model including all potential risk factors. Using this logistic regression model, we identified the risk factors associated with an increased fracture risk (adjusted OR of $\geq 1.30$ with a significance level of $<0.05)$. Patients were then classified according to the number of those risk factors present. To evaluate the effects on nonosteoporotic fractures, fractures of the carpus, tibia/fibula/ankle, skull, foot, and patella were grouped together. These fracture types did not show an apparent increase in incidence with advancing age. ${ }^{23}$

As all fracture cases were collected from the GPRD, incidence rates of fracture could be calculated. We analyzed the fracture incidence stratified by the number of risk factors (de- tailed incidence estimates are available from the corresponding author). For each risk factor category, the number of patients with a fracture was divided by the person-years of follow-up. The follow-up for each risk factor category was estimated using the proportion of patients within the control population who had a similar number of risk factors (this proportion was estimated separately for each 5 year age and gender stratum). These proportions were then multiplied by the total GPRD follow-up to derive the follow-up for the risk factor category. Further details on the methods and limitations of calculating fracture incidence in this population can be found elsewhere. ${ }^{23}$

\section{Statistical Analysis}

The predictive value of medical and drug history on the occurrence of fracture was evaluated using two different approaches. First, on a randomly selected subpopulation consisting of one half of the fracture patients (and their controls), an unconditional logistic regression function was fitted to find the sets of predictors that best predicted fractures. This was based on a backward regression model (with a significance level of 0.25 ) that initially included all risk factors and was done separately for each fracture type. The screening characteristics of the regression function (i.e., the predicted odds of fracture for each patient) were tested on the other half of the study population. Receiver operator characteristic (ROC) curves, which plot the sensitivity (true positive rate) vs 1 minus the specificity (false positive rate) for all possible cutoff point values, were constructed. ${ }^{10}$ Areas under the ROC curve were estimated. The ROC curve describes the accuracy of a test over a range of cutoff points. The area under the ROC curve provides the overall accuracy of a test: the larger the area, the better the test. The optimal cutoff point for the sensitivity and specificity of each fracture type was evaluated by estimating the point with the largest sensitivity and specificity combined. ${ }^{11}$ The positive predictive value was computed using the sensitivity, specificity, and proportion of patients who developed a fracture over a 5 year period. This proportion was estimated using the age- and gender-specific GPRD fracture incidence rates and the mortality rates of the general population in England and Wales. ${ }^{19}$ This analysis was done for patients aged $50-64$ years and for those aged $\geq 65$ years.

The second approach to fracture prediction was based on the number of risk factors. For patients aged $\geq 65$ years, the sensitivity and specificity was estimated for different thresholds (one or more, two or more, or three or more risk factors). The calculation of positive predictive value was done separately for patients with a first fracture and for those with a later fracture at a different skeletal site.

\section{Results}

The study population consisted of 231,778 adult patients who sustained a fracture during follow-up. A total of 77,828 fracture cases were aged $\geq 65$ years. The most frequent fracture types were radius/ulna $(44,201$ patients), carpus $(38,202)$, and tibia/ fibula/ankle $(30,195)$. Femoral/hip fractures occurred in 22,250 and were vertebral in 8712 patients. The average age of the fracture cases was 50 years and $52.5 \%$ were women (Table 1). The control population had a similar age and gender distribution as they were matched on these characteristics. The following diseases and drugs were independently associated with an increased risk of fractures (adjusted OR $>1.30$ ) and included in the analysis: history of anemia (OR 1.4; 95\% confidence interval [CI] 1.3-1.5), dementia (OR 1.6; CI 1.5-1.7), cerebrovascular disease (OR 1.3; CI 1.3-1.4), and chronic obstructive pulmonary disease (OR 1.4; CI 1.4-1.5) and also recent use of oral corti- 
Table 1. Characteristics of fracture cases and controls

\begin{tabular}{lcccc}
\hline & $\begin{array}{c}\text { No. of cases } \\
(\mathrm{n}=231,778)\end{array}$ & $\begin{array}{c}\text { No. of controls } \\
(\mathrm{n}=231,778)\end{array}$ & $\begin{array}{c}\text { Crude OR } \\
(95 \% \text { CI })\end{array}$ & $\begin{array}{c}\text { Adjusted OR } \\
(95 \% \text { CI })\end{array}$ \\
\hline Age (years) & & & - & - \\
$\quad$ Mean & 51.7 & 51.5 & - & - \\
$\quad$ Median & 50 & 50 & - & - \\
Number of women & $121,615(52.5 \%)$ & $121,615(52.5 \%)$ & & \\
Disease history & & & & \\
$\quad$ COPD & $41,912(18.1 \%)$ & $28,542(12.3 \%)$ & $1.6(1.6-1.6)$ & $1.4(1.4-1.5)$ \\
$\quad$ Cerebrovascular disease & $10,846(4.7 \%)$ & $7545(3.3 \%)$ & $1.5(1.5-1.6)$ & $1.3(1.3-1.4)$ \\
Dementia & $4173(1.8 \%)$ & $2412(1.0 \%)$ & $1.8(1.7-1.9)$ & $1.6(1.5-1.7)$ \\
$\quad$ Anemia & $4117(1.8 \%)$ & $2611(1.1 \%)$ & $1.6(1.5-1.7)$ & $1.4(1.3-1.5)$ \\
Drug use in 6 months before & & & & \\
$\quad$ NSAIDs & $32,209(13.9 \%)$ & $21,013(9.1 \%)$ & $1.6(1.6-1.7)$ & $1.6(1.5-1.6)$ \\
$\quad$ Hypnotics/anxiolytics & $22,328(9.6 \%)$ & $14,466(6.2 \%)$ & $1.7(1.6-1.7)$ & $1.3(1.3-1.4)$ \\
$\quad$ Antidepressants & $16,449(7.1 \%)$ & $9416(4.1 \%)$ & $1.8(1.8-1.9)$ & $1.5(1.5-1.5)$ \\
$\quad$ Oral corticosteroids & $7704(3.3 \%)$ & $4040(1.7 \%)$ & $2.0(1.9-2.0)$ & $1.4(1.4-1.5)$ \\
$\quad$ Anticonvulsants & $5282(2.3 \%)$ & $2232(1.0 \%)$ & $2.4(2.3-2.5)$ & $2.1(2.0-2.2)$ \\
$\quad$ Anti-Parkinson & $2808(1.2 \%)$ & $1470(0.6 \%)$ & $1.9(1.8-2.1)$ & $1.5(1.4-1.6)$ \\
$\quad$ Antiarrythmic drugs & $1587(0.7 \%)$ & $930(0.4 \%)$ & $1.7(1.6-1.9)$ & $1.5(1.4-1.6)$ \\
\hline
\end{tabular}

KEY: CI, confidence interval; COPD, chronic obstructive pulmonary disease; OR, odds ratio; NSAIDs, nonsteroidal anti-inflammatory drugs.

costeroids (OR 1.4; CI 1.4-1.5), anticonvulsants (OR 2.1; CI 2.0-2.2), NSAIDs (OR 1.6; CI 1.5-1.6), antiarrythmics (OR 1.5; CI 1.4-1.6), hypnotics/anxiolytics (OR 1.3, CI 1.3-1.4), antidepressants (OR 1.5; CI 1.5-1.5), or anti-Parkinson drugs (OR 1.5; CI 1.4-1.6). A history of one of these risk factors was found in $42.3 \%$ of cases and $29.3 \%$ of controls.

Table 2 provides the ORs for fracture according to the number of strong risk factors present. It was found that fracture risk was strongly related to the number of risk factors. The OR of a femur/hip fracture was 4.6 in patients with three or more risk factors compared to patients without any risk factor. For verte- bral fracture, this OR was 8.1. The presence of risk factors had smaller effects on the risk of radius/ulna fracture (OR of 2.0 with three or more risk factors). There were no major differences between men and women regarding the effects of disease and drug history on fracture risk. In women, the OR of fracture was 1.7 with one risk factor, 2.3 with two risk factors, and 3.2 with three or more risk factors. For men, these ORs were 1.7, 2.4, and 3.5 , respectively. Similar effects were also observed across age. The ORs of fracture by number of risk factors were 1.6, 2.0, and 2.8 , respectively, for patients aged 50-64 years and 1.7, 2.2, and 3.2 for patients aged $\geq 65$ years.

Table 2. ORs of fractures with number of strong risk factors (i.e., those with an OR of fracture $\geq 1.30$ )

\begin{tabular}{|c|c|c|c|c|c|}
\hline No. of risk factors & & No. of cases & No. of controls & OR & $95 \% \mathrm{CI}$ \\
\hline \multirow[t]{4}{*}{ Any fracture } & 0 & 133,746 & 163,917 & 1.0 & - \\
\hline & 1 & 62,157 & 47,775 & 1.7 & $1.7-1.7$ \\
\hline & 2 & 24,082 & 14,770 & 2.3 & $2.2-2.3$ \\
\hline & $3^{+}$ & 11,793 & 5316 & 3.2 & $3.1-3.4$ \\
\hline \multirow[t]{4}{*}{ Radius/ulna } & 0 & 25,505 & 29,621 & 1.0 & - \\
\hline & 1 & 12,110 & 9953 & 1.5 & $1.4-1.5$ \\
\hline & 2 & 4535 & 3326 & 1.7 & $1.6-1.8$ \\
\hline & $3^{+}$ & 2051 & 1301 & 2.0 & $1.9-2.2$ \\
\hline \multirow[t]{4}{*}{ Femur/hip } & 0 & 7431 & 12,161 & 1.0 & - \\
\hline & 1 & 7138 & 6129 & 2.0 & $1.9-2.1$ \\
\hline & 2 & 4672 & 2794 & 2.9 & $2.8-3.1$ \\
\hline & $3^{+}$ & 3009 & 1166 & 4.6 & $4.3-5.0$ \\
\hline \multirow[t]{4}{*}{ Vertebral } & 0 & 3250 & 5493 & 1.0 & - \\
\hline & 1 & 2764 & 2090 & 2.6 & $2.4-2.9$ \\
\hline & 2 & 1601 & 831 & 4.2 & $3.8-4.7$ \\
\hline & $3^{+}$ & 1097 & 298 & 8.1 & $7.0-9.4$ \\
\hline \multirow[t]{4}{*}{ Nonosteoporotic ${ }^{\mathrm{a}}$} & 0 & 72,351 & 83,956 & 1.0 & - \\
\hline & 1 & 26,893 & 19,480 & 1.7 & $1.6-1.7$ \\
\hline & 2 & 7537 & 4596 & 2.1 & $2.0-2.2$ \\
\hline & $3^{+}$ & 2653 & 1402 & 2.5 & $2.4-2.7$ \\
\hline \multirow{4}{*}{ Other $^{\mathrm{b}}$} & 0 & 22,246 & 28,762 & 1.0 & - \\
\hline & 1 & 11,787 & 9159 & 1.8 & $1.7-1.9$ \\
\hline & 2 & 5182 & 2978 & 2.6 & $2.5-2.7$ \\
\hline & $3^{+}$ & 2744 & 1060 & 3.9 & $3.6-4.3$ \\
\hline
\end{tabular}

KEY: CI, confidence interval; OR, odds ratio.

${ }^{a}$ Carpus, tibia/fibula/ankle, skull, foot, and patella.

${ }^{\mathrm{b}}$ Humerus/ribs/pelvis/clavicle/scapula. 
Any fracture

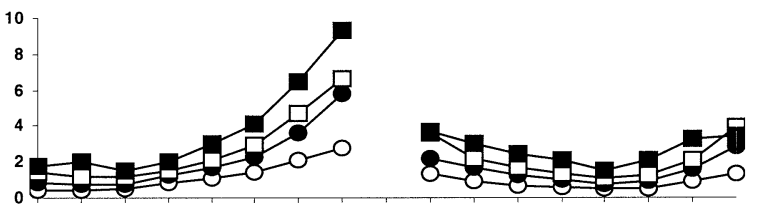

Humerus

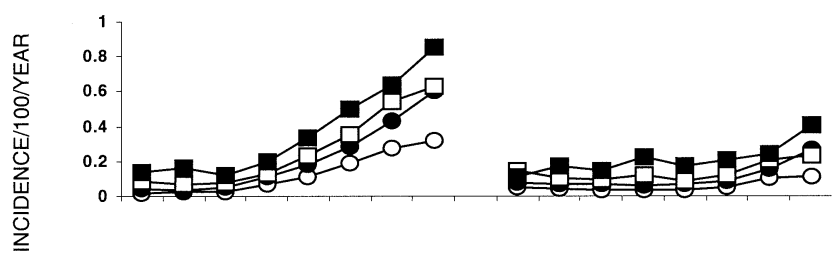

Femur/hip

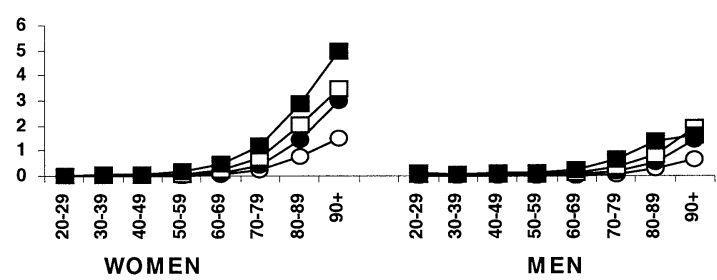

Vertebral

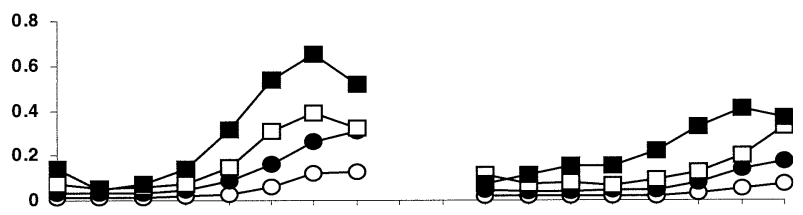

Radius/ulna

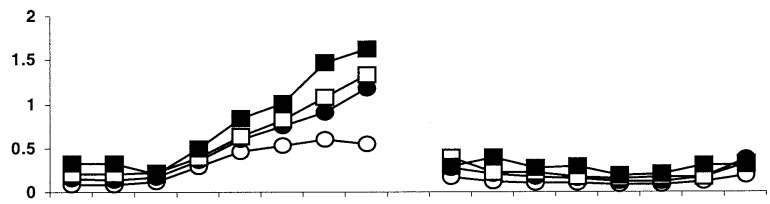

Tibia/fibula/ankle

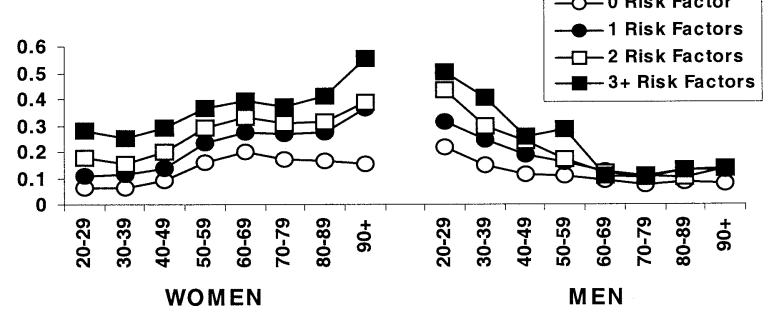

Figure 1. Incidence of fractures stratified by age, gender, and number of risk factors.

The age- and gender-specific incidence rates of various fractures stratified by number of risk factors are shown in Figure 1. Men and women without risk factors generally had the lowest fracture risks across all age groups, whereas patients with three or more risk factors had the highest rates. The rate of femur/hip fracture was 5.0 cases per 100 person-years in women aged $\geq 90$ years with three or more risk factors, compared with 1.5 in women without any risk factor. For men, these figures were 1.6 and 0.6 , respectively.

Fracture history and number of risk factors were found to be strong predictors of fracture in both women and men. For women aged $\geq 65$ years and without a history of fractures, the rate of fracture increased from 1.3 in women without risk factors, 2.2 with one risk factor, 2.7 with two risk factors, and 3.8 in women with three or more risk factors. In women with a fracture history, these rates were $3.8,4.7,5.6$, and 7.0, respectively. These rates were $0.5,0.9,1.2$, and 1.8 in elderly men without fracture history and $2.3,3.2,3.8$, and 4.9 , respectively, in men with a fracture history.

Figure 2 shows the performance of a screening tool based on disease and drug history in patients aged $\geq 65$ years. Vertebral fractures were predicted well; in contrast, the tool had little value in predicting radius/ulna fractures. Risk factor information appeared to predict fractures similarly well in both men and women. The ROC curves, which plot the true positive rate (sensitivity) against the false positive rates (1 minus specificity), were also comparable between genders for the various fracture types.

Table 3 shows the properties of disease and drug history in discriminating fracture cases from controls (aged $\geq 65$ years). The sensitivity indicates the proportion of fracture cases classified correctly by the model; the specificity indicates the propor- tion of correctly classified controls. The positive predictive value indicates the probability that a person classified as a fracture case by the model did indeed suffer a fracture within a 5 year period. Vertebral and femur/hip fractures were predicted relatively efficiently by the risk factors with areas under the curve of $79 \%$ for vertebral, and $65 \%$ for femoral/hip fractures. The positive predictive value of the risk-prediction model for any fracture was $10.9 \%$ for women aged $\geq 65$ years and $20.0 \%$ in women aged 85 years. A risk-prediction model was also developed separately for people aged 50-64 years. The positive predictive value was $5.9 \%$ for women and $5.2 \%$ for men aged 50 years.

Fracture prediction improved when fracture history was added to medical and drug history (Table 4). The positive predictive value was $8.4 \%$ for women aged $\geq 65$ years without any risk factors and fracture history compared with $26.8 \%$ in those with three or more risk factors, and $40.7 \%$ in women aged 85 years with three or more risk factors and a history of fractures. This analysis was also done for people aged 50-64 years. The positive predictive value was $5.4 \%$ for women aged 50 years without any risk factors and fracture history compared with $22.7 \%$ in those with three or more risk factors. For men of similar age, these figures were $4.4 \%$ and $20.4 \%$, respectively.

\section{Discussion}

In this study, we found that fracture risk was strongly related to a number of clinical risk factors routinely recorded in primary care. Elderly patients with these risk factors and a history of fracture had especially high fracture risk. The medical risk factors did not predict the occurrence of fracture in an individual patient with any certainty, but did allow identification of groups of patients with a substantial increase in fracture risk, who might 


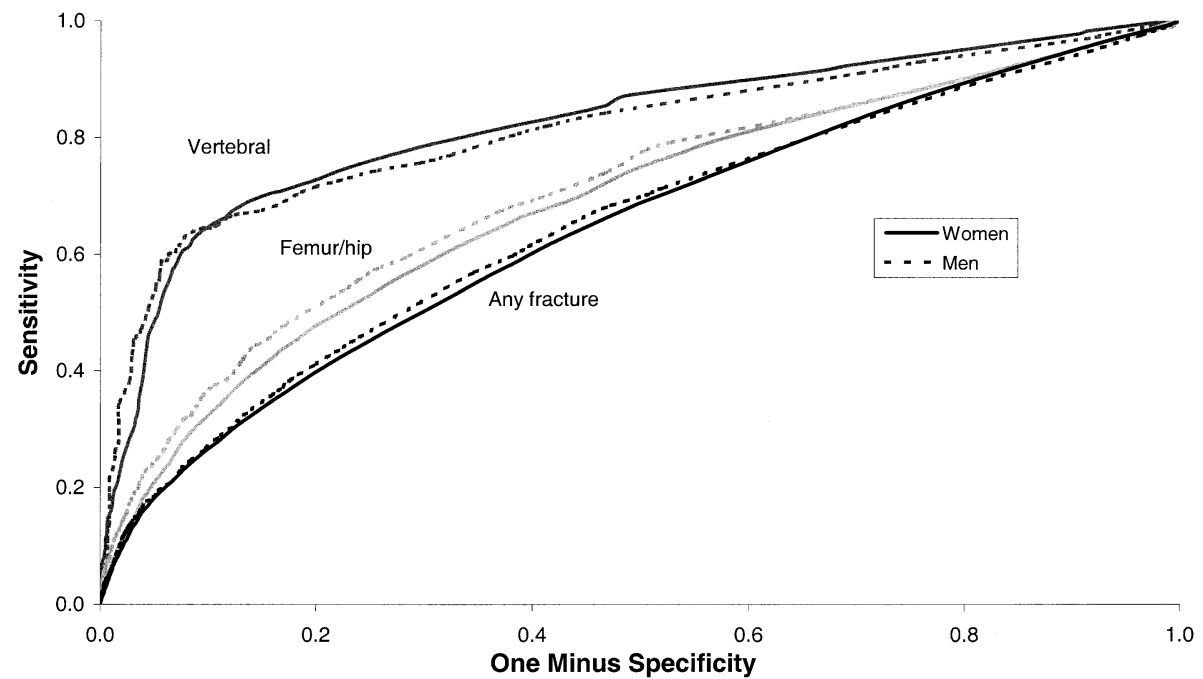

Figure 2. Receiver operator characteristic (ROC) curves for femur/hip, vertebra, and any type of fractures stratified by gender in patients aged $\geq 65$ years.

be amenable to further investigation. The risk-prediction tool, developed on the basis of medical risk factors, showed similar screening characteristics among men and women.

Several guidelines for the management of osteoporosis ${ }^{4,12,20}$ suggest that bone densitometry is best used in patients with radiological evidence of osteopenia or vertebral deformity, in those with a history of fragility fractures, and among those with certain clinical risk factors. Unfortunately, many of these clinical risk factors are not routinely recorded in primary care. It is therefore difficult to use risk factor schedules to identify patients retrospectively in the primary care setting. However, some of these risk factors pertain to previous medical and drug history (information that is recorded accurately in most primary care settings). We found that a combination of even a few such medical risk factors yielded relative rates of almost five for femur/hip fracture and eight for vertebral fracture. Our findings support the notion that such risk profiles might permit the identification of groups of patients in primary care who are at increased risk of fracture, and who might benefit from assessment of bone density.

Table 3. Screening characteristics for fracture prediction in patients aged $\geq 65$ years on the basis of a logistic function including disease and drug history

\begin{tabular}{|c|c|c|c|c|c|c|c|c|}
\hline \multirow[b]{3}{*}{ Fracture history } & \multirow[b]{3}{*}{$\begin{array}{l}\text { No. of } \\
\text { cases }\end{array}$} & \multirow[b]{3}{*}{$\begin{array}{c}\text { Area } \\
\text { under ROC }\end{array}$} & \multicolumn{6}{|c|}{ Optimum screen } \\
\hline & & & \multirow[b]{2}{*}{ Sensitivity } & \multirow[b]{2}{*}{ Specificity } & \multicolumn{4}{|c|}{ Positive predictive value } \\
\hline & & & & & $\begin{array}{l}\text { Women } \\
65 \text { years }\end{array}$ & $\begin{array}{c}\text { Men } \\
65 \text { years }\end{array}$ & $\begin{array}{l}\text { Women } \\
85 \text { years }\end{array}$ & $\begin{array}{l}\text { Men } \\
85 \text { years }\end{array}$ \\
\hline Any fracture & 38,914 & $58 \%$ & $58.4 \%$ & $62.6 \%$ & $10.9 \%$ & $4.4 \%$ & $20.0 \%$ & $9.1 \%$ \\
\hline Femur/hip & 9631 & $65 \%$ & $61.1 \%$ & $68.3 \%$ & $1.4 \%$ & $0.6 \%$ & $11.6 \%$ & $4.5 \%$ \\
\hline Radius/ulna & 9282 & $50 \%$ & $56.2 \%$ & $58.3 \%$ & $3.6 \%$ & $0.5 \%$ & $4.2 \%$ & $0.9 \%$ \\
\hline Vertebral & 2439 & $79 \%$ & $66.4 \%$ & $89.3 \%$ & $2.3 \%$ & $1.1 \%$ & $5.4 \%$ & $3.3 \%$ \\
\hline Nonosteoporotic & 8583 & $51 \%$ & $64.0 \%$ & $50.0 \%$ & $3.1 \%$ & $1.5 \%$ & $2.5 \%$ & $1.3 \%$ \\
\hline Other & 8443 & $59 \%$ & $59.2 \%$ & $64.6 \%$ & $2.5 \%$ & $1.5 \%$ & $5.8 \%$ & $3.0 \%$ \\
\hline
\end{tabular}

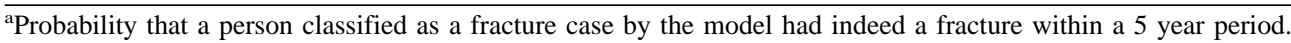

Table 4. Screening characteristics for fracture prediction in patients aged $\geq 65$ years on the basis of fracture history and number of risk factors

\begin{tabular}{|c|c|c|c|c|c|c|c|}
\hline \multirow[b]{3}{*}{$\begin{array}{l}\text { Fracture } \\
\text { history }\end{array}$} & \multirow[b]{3}{*}{$\begin{array}{l}\text { No. of risk } \\
\text { factors }\end{array}$} & \multicolumn{6}{|c|}{ Optimum screen } \\
\hline & & \multirow[b]{2}{*}{ Sensitivity } & \multirow[b]{2}{*}{ Specificity } & \multicolumn{4}{|c|}{ Positive predictive value ${ }^{a}$} \\
\hline & & & & $\begin{array}{l}\text { Women } \\
65 \text { years }\end{array}$ & $\begin{array}{c}\text { Men } \\
65 \text { years }\end{array}$ & $\begin{array}{l}\text { Women } \\
85 \text { years }\end{array}$ & $\begin{array}{c}\text { Men } \\
85 \text { years }\end{array}$ \\
\hline \multirow[t]{3}{*}{ No } & $\geq 1$ & $63.6 \%$ & $52.9 \%$ & $8.4 \%$ & $3.3 \%$ & $14.5 \%$ & $7.1 \%$ \\
\hline & $\geq 2$ & $30.4 \%$ & $81.9 \%$ & $10.2 \%$ & $4.1 \%$ & $17.4 \%$ & $8.7 \%$ \\
\hline & $\geq 3$ & $11.2 \%$ & $94.7 \%$ & $12.5 \%$ & $5.1 \%$ & $21.0 \%$ & $10.7 \%$ \\
\hline \multirow[t]{3}{*}{ Yes } & $\geq 1$ & $63.6 \%$ & $52.9 \%$ & $18.9 \%$ & $12.3 \%$ & $30.4 \%$ & $18.4 \%$ \\
\hline & $\geq 2$ & $30.4 \%$ & $81.9 \%$ & $22.5 \%$ & $14.9 \%$ & $35.2 \%$ & $21.9 \%$ \\
\hline & $\geq 3$ & $11.2 \%$ & $94.7 \%$ & $26.8 \%$ & $18.1 \%$ & $40.7 \%$ & $26.1 \%$ \\
\hline
\end{tabular}

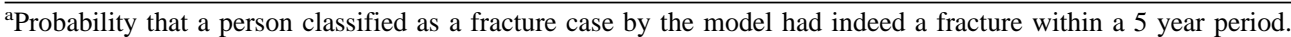


Bone density is one of the strongest determinants of fracture risk. A recent meta-analysis ${ }^{16}$ estimated that, with a lifetime fracture incidence of $3 \%$, the positive predictive value of bone density measurement (using a threshold of 1 SD below the age-adjusted mean) would be $9 \%$. With an incidence of $30 \%$, the probability of a fracture given low bone density would rise to $58 \%$. At these lifetime incidence rates, the positive predictive values based on the medical risk factors included in our study would be $5 \%$ and $40 \%$, respectively. Further evidence that medical risk factors might perform reasonably well in comparison with bone densitometry emerges from the Study of Osteoporotic Fractures $^{8}$ in which the prediction of hip fracture by bone density gave an area under the ROC curve of $76 \%$ for measurements at the total proximal femur and $62 \%$ for measurements of the lumbar spine. In our study, this area was $65 \%$ on the basis of previous fracture history and medical risk factors. Finally, other studies have suggested that the combination of risk factors with bone density measurement may help to improve the predictive capacity of each measure for future fracture. ${ }^{2,3}$

Our results are comparable to other published reports. In the Melton Mowbray Osteoporotic Fracture Study, ${ }^{17}$ it was found that a combination of readily obtained risk factors was capable of identifying elderly women who later sustained a hip fracture. These included weight, poor trunk maneuver, epilepsy, kyphosis, poor circulation of the foot, and short-term corticosteroid use. The area under the ROC curve in their analysis was $82 \% .{ }^{17}$ The Rotterdam Study ${ }^{3}$ estimated an area under the ROC curve of $83 \%$ for hip fracture prediction based on age, gender, weight, height, use of a walking aid, and cigarette smoking. The corresponding figure was $71 \%$ in the Study of Osteoporotic Fractures, where the risk score utilized age, weight, fracture history, maternal fracture history, use of arms to stand up from a chair, and cigarette smoking. ${ }^{2}$ These results are in contrast to the findings from two studies that evaluated vertebral fracture showing that risk factors were not sufficiently predictive of vertebral fracture risk. ${ }^{6,15}$ This may have been related to the number and type of risk factors considered.

The pathogenesis of fracture entails a complex interaction between osteoporosis and propensity to trauma. A large number of genetic and environmental risk factors for fracture have been identified, including gender, body build, lifestyle characteristics, gonadal steroid deficiency, chronic diseases associated with osteoporosis, and use of certain medications such as corticosteroids. Individual risk factors are likely to have limited value in predicting the occurrence of fracture, given the multifactorial etiology. It has been estimated that, in the case of a risk factor with a relative risk for disease of $<5.0$, most cases will not have the risk factor and will consequently not be identified in riskbased preventive strategies. ${ }^{1}$ Risk factors may have better discriminatory capacity when combined. Consistent with this, we observed that the addition of comorbidity and drug use to age and previous fracture history allowed for identification of patients with a higher risk of fracture. However, the problem with the clinical utility of this approach is that the majority of fractures do not occur in the groups with the highest numbers of risk factors. Thus, in our study, only around one in eight hip fractures, and a similar proportion of vertebral fractures, fell into the highest risk category. Consequently, the number of factors per se could probably not be used as an adequate screening test. It might, however, comprise a useful threshold for which to undertake further risk factor ascertainment and/or measurement of bone density.

Most studies evaluating the predictive capacity of historical risk factors for future fracture have focused on women. ${ }^{2,6,15,17}$ However, in a large epidemiological study of hip fracture con- trasting risk factors between men and women, the associations with chronic medical disorders, physical activity, and cigarette smoking were generally similar for both genders. ${ }^{18}$ This finding is consistent with the results of a previous British case-control study of hip fracture. ${ }^{7}$ Our study adds to these epidemiological observations and suggests that risk factors are similar in their predictive capacity for future fracture in men and women.

One limitation of our study is the possibility of detection bias. A history of many risk factors may have increased the likelihood of fracture diagnosis due to greater awareness among physicians. However, the use of osteoporosis medication prior to the fracture was low across all risk factor groups. A second limitation is that the risk factors included in the study were limited to diseases and drugs. We did not have information on maternal fracture history and genetic or lifestyle factors; furthermore, we did not take into account the severity of disease, dose, or duration of drug treatments and whether the disease was more active in the period of time closer to the fracture. It is likely that with more detailed information the identification of high-risk groups can be further improved. Finally, we could not exclude high-trauma fractures. As such fractures are not related to osteoporosis, inclusion of these fractures may have underestimated the utility of risk factor information.

In conclusion, the data suggest that routinely recorded medical risk factors permit identification of groups of patients with a substantial increase in future risk of fracture. Further investigations, such as bone densitometry, might be conveniently targeted at this group of patients.

Acknowledgments: The study was funded by Procter \& Gamble Pharmaceuticals. The authors thank EPIC, the GPRD license holder, for their support. The manuscript was prepared by Gill Strange.

\section{References}

1. Baron, J. A. The clinical utility of risk factor data. J Clin Epidemiol 42:10131020; 1989

2. Black, D. M., Steinbuch, M., Palermo, L., Dargent-Molina, P., Lindsay, R., Hoseyni, M. S., and Johnell, O. An assessment tool for predicting fracture risk in postmenopausal women. Osteopor Int 12:519-528; 2001.

3. Burger, H., De Laet, C. E. D. H., Weel, A. E. A. M., Hofman, A., and Pols, H. A. P. Added value of bone mineral density in hip fracture risk scores. Bone 25:369-374; 1999.

4. Compston, J. E., Cooper, C., and and Kanis, J. A. Bone densitometry in clinical practice. Br J Med 310:1507-1510; 1995.

5. Consensus Development Conference. Prophylaxis and treatment of osteoporosis. Am J Med 90:107-110; 1991

6. Cooper, C., Shah, S., Hand, D. J., Adams, J., Compston, J., Davie, M., and Woolf, A. Screening for vertebral osteoporosis using individual risk factors. Osteopor Int 2:48-53; 1991.

7. Cooper, C., Wickham, C., and and Barker, D. J. P. Physical activity, muscle strength, and calcium intake in fracture of the proximal femur in Britain. $\mathrm{Br}$ Med J 297:1443-1446; 1988.

8. Cummings, S. R., Black, D. M., Nevitt, M. C., Browner, W., Cauley, J., Ensrud, K., Genant, H. K., Palermo, L., Scott, J., and Vogt, T. M. Bone density at various sites for prediction of hip fractures. Lancet 341:72-75; 1993.

9. Cummings, S. R., Nevitt, M. C., Browner, W. S., Stone, K., Fox, K. F., Ensrud, K. E., Cauley, J., Black, D., and Vogt, T. M. Risk factors for hip fractures in white women. N Engl J Med 332:767-773; 1995.

10. Fletcher, R. H., Fletcher, S. W., and Wagner, E. H. Clinical Epidemiology: The Essentials. 2nd Ed. Baltimore: Williams \& Wilkins; 1988.

11. Green, M. C. Evaluating the discriminatory power of a multiple regression model. Stat Med 7:519-524; 1988.

12. Kanis, J. A., Delmas, P., Burckhardt, P., Cooper, C., and Torgerson, D. Guidelines for diagnosis and management of osteoporosis. Osteopor Int 7:390406; 1997. 
13. Kanis, J. A., Johnell, O., Oden, A., Jonsson, B., Dawson, A., and Dere, W. Risk of hip fracture derived from relative risks: An analysis applied to the population of Sweden. Osteopor Int 11:120-127; 2000.

14. Kanis, J. A. and Pitt, F. A. Epidemiology of osteoporosis. Bone 13(Suppl.): S7-S15; 1992.

15. Kleerekoper, M., Peterson, E., Nelson, D., Tilley, B., Phillips, E., Schork, M. A., and Kuder, J. Identification of women at risk for developing postmenopausal osteoporosis with vertebral fractures: Role of history and single photon absorptiometry. Bone Miner 7:171-86; 1989.

16. Marshall, D., Johnell, O., and Wedel, H. Meta-analysis of how well measures of bone mineral density predict occurrence of osteoporotic fractures. Br Med J 312:1254-1259; 1996

17. McGrother, C. W., Donaldson, M. M. K., Clayton, D., Abrams, K. R., and Clarke, M. Evaluation of hip fracture risk score for assessing elderly women: The Melton Osteoporotic Fracture (MOF) Study. Osteopor Int 13:89-96; 2002.

18. Meyer, H. E., Tverdal, A., and Falch, J. A. Risk factors for hip fracture in middle-aged Norwegian women and men. Am J Epidemiol 137:1203-1211; 1993.

19. Office for Population Censuses and Surveys. Mortality Statistics: Review of the Registrar General on Deaths by Cause, Sex, and Age in England and Wales, 1992. London: HMSO; 1993.
20. Royal College of Physicians. Clinical Guidelines for the Prevention and Treatment of Osteoporosis. London: RCP; 1999.

21. Shane, E. Osteoporosis associated with illness and medications. In: Marcus, R. Feldman, D., and Kelsey, J., eds. Osteoporosis. San Diego, CA: Academic; p. 925-946; 1996.

22. van Staa, T. P., Abenhaim, L., Cooper, C., Begaud, B., Zhang, B., and Leufkens, H. G. M. The use of a large pharmaco-epidemiological database to study exposure to oral corticosteroids and risk of fractures: Validation of study population and results. Pharmacoepidemiol Drug Safety 9:359-366; 2000.

23. van Staa, T. P., Dennison, E. M., Leufkens, H. G. M., and Cooper, C. Epidemiology of fractures in England and Wales. Bone 29:517-522; 2001

24. Walley, T. and Mantgani, A. The UK General Practice Research Database. Lancet 350:1097-1099; 1997.
Date Received: February 14, 2000

Date Revised: June 13, 2002

Date Accepted: June 13, 2002 